SOUZA, L.R. et al. Desempenho de bovinos Nelore suplementados com óleos essenciais de caju e mamona, mantidos em pastagens de Brachiária brizantha. PUBVET, Londrina, V. 8, N. 6, Ed. 255, Art. 1692, Março, 2014.

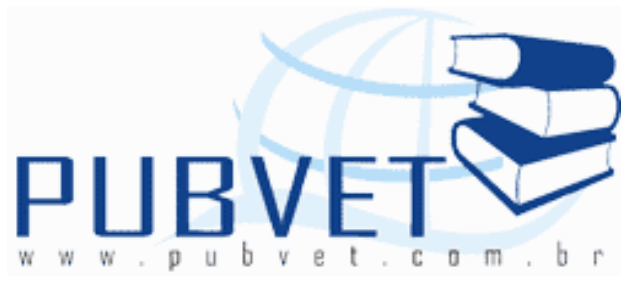

PUBVET, Publicações em Medicina Veterinária e Zootecnia.

\title{
Desempenho de bovinos Nelore suplementados com óleos essenciais de caju e mamona, mantidos em pastagens de Brachiária brizantha
}

\author{
Lívia Rezende de Souza ${ }^{1}$, Rodrigo Zaiden Taveira ${ }^{2}$, Renato Tângari Dib ${ }^{2}$, \\ Osvado José da Silveira Neto²
}

${ }^{1}$ Zootecnista formado pela Universidade Estadual de Goiás - UEG; Unidade Universitária de São Luís de Montes Belos, GO;

2 Docente e Pesquisador - Universidade Estadual de Goiás - UEG; Unidade Universitária de São Luís de Montes Belos, GO.

\section{Resumo}

A utilização de óleos essenciais na dieta de bovinos e seus mecanismos estão sendo bastante estudados, tais como o uso de óleos de caju e mamona. Assim, objetivou - se avaliar os efeitos de óleos essenciais de caju e mamona na suplementação mineral de bovinos mantidos em regime de pastagem Brachiáriabrizantha no estado do Tocantins. Os animais foram pesados e divididos aleatoriamente em dois grupos no início do período experimental que totalizou 60 dias entre os meses de setembro e novembro, com 60 bovinos na ocasião do sobreano (15 meses de idade) cada grupo. A pastagem apresentava boa disponibilidade de massa foliar, porém seca. O grupo testemunha recebeu suplemento mineral sem óleos essenciais + pastagem + água à vontade. O grupo tratamento recebeu suplemento mineral com óleos essenciais $(2,43 \mathrm{~g} /$ animal/dia $)+$ pastagem + água à vontade. As análises 
SOUZA, L.R. et al. Desempenho de bovinos Nelore suplementados com óleos essenciais de caju e mamona, mantidos em pastagens de Brachiária brizantha. PUBVET, Londrina, V. 8, N. 6, Ed. 255, Art. 1692, Março, 2014.

estatísticas foram realizadas pelo programa estatístico SAS e as médias comparadas pelo teste $t(p<0,05)$. O consumo de suplemento mineral foi maior para o grupo tratamento (180g/animal/dia) que o grupo testemunha (165g/animal/dia). A inclusão de óleos essenciais na suplementação promoveu ganho em peso médio de $17,36 \mathrm{~kg}$ contra $6,53 \mathrm{~kg}$ para o grupo testemunha em todo o período experimental. Houve diferença estatística $(p<0,05)$ entre os dois tratamentos.

Palavras-chave: Aditivos, consumo, ganho em peso, massa foliar, suplemento mineral.

\title{
Performance of Nellore supplemented with essential oils and castor cashew, grazing on Brachiaria Brizantha
}

\begin{abstract}
The use of essential oils in the diet of cattle and their mechanisms are being extensively studied, such as the use of castor oil and cashew. Thus, the objective - to evaluate the effects of essential oils of castor and cashew in mineral supplementation of cattle kept on pasture Brachiariabrizantha in the state of Tocantins. The animals were weighed and randomly divided into two groups at the beginning of the experimental period totaling 60 days between the months of September and November, with 60 cattle at the time of the yearling (15 months) each group. The pasture had good availability of leaf mass, but drought. The control group received no supplement mineral oils + pasture + water ad libitum. The treatment group received mineral supplement with essential oils (2.43 g / animal / day) + pasture + water ad libitum. Statistical analyzes were performed by SAS statistical software and means were compared by t-test $(p<0.05)$. The mineral supplement intake was higher in the treatment group $(180 \mathrm{~g} / \mathrm{animal} / \mathrm{dia})$ than the control group (165g/animal/dia). The inclusion of supplementation on essential oils promoted average weight gain of $17.36 \mathrm{~kg}$ versus $6.53 \mathrm{~kg}$ for the control group
\end{abstract}


SOUZA, L.R. et al. Desempenho de bovinos Nelore suplementados com óleos essenciais de caju e mamona, mantidos em pastagens de Brachiária brizantha. PUBVET, Londrina, V. 8, N. 6, Ed. 255, Art. 1692, Março, 2014.

throughout the experimental period. There was a statistical difference ( $p$ $<0.05)$ between the two treatments.

Keyword: Additives, consumption, weight gain, leaf mass, mineral supplement.

\section{Introdução}

A expansão da pecuária brasileira e crescente aumento do rebanho bovino são reflexos das técnicas de manejo utilizadas nos últimos anos, tais como melhorias na nutrição, manejo, sanidade e reprodução. Segundo o IBGE (2012), no $1^{\circ}$ trimestre de 2012 foram abatidas 7,219 milhões de cabeças de bovinos, representando queda de $2,0 \%$ em relação ao trimestre imediatamente anterior e aumento de 1,6\% frente ao mesmo período de 2011. As regiões Centro- oeste e Norte tiveram maior aumento em sua taxa de desfrute, porém o Estado do Tocantins apresentou queda de $2 \%$ em relação ao primeiro trimestre de 2011.

Nas condições brasileiras, a estacionalidade forrageira é a fase mais crítica do sistema de produção de bovinos em pastejo. No período de menor oferta de forragem o rebanho bovino alimenta-se de pastagem de baixo valor nutritivo, oriunda do crescimento do período de primavera/verão, caracterizadas por apresentar elevado teor de fibra indigestível e teores de proteína bruta inferiores a 7\% na matéria seca, além da baixa quantidade de minerais (CARLOTO, 2008).

O método mais eficiente de fornecer minerais para bovinos é através da suplementação mineral. Independentemente do tipo de suplemento utilizado é de fundamental importância que nas formulações ocorra ainclusão de aditivos zootécnicos melhoradores de desempenho, uma vez que este tipo de "tecnologia" proporciona melhor aproveitamento energético da forragem, ambiente ruminal mais estável e até $25 \%$ a mais de desempenho, quando comparado aos suplementos sem sua inclusão (COAN \& GRANDINI, 2012). 
SOUZA, L.R. et al. Desempenho de bovinos Nelore suplementados com óleos essenciais de caju e mamona, mantidos em pastagens de Brachiária brizantha. PUBVET, Londrina, V. 8, N. 6, Ed. 255, Art. 1692, Março, 2014.

É muito comum a utilização de aditivos como ionóforos e virginiamicina para avaliação de desempenho de bovinos em confinamento ou em suplementação protéica e energética. Todavia, são escassos os estudos que comprovem a eficácia destes aditivos, principalmente aditivos naturais como óleos essenciais, ao utilizar apenas o suplemento mineral e o sódio como veículo em pastagem.

Os óleos essenciais são classificados junto ao Ministério da Agricultura, Pecuária e Abastecimento como aditivo aromatizante destinado a fabricantes de alimentos para aves e ruminantes com o objetivo de auxiliar na melhora de desempenho dos animais. O produto comercial a partir de óleo de caju e mamona possui como veículo a vermiculita, que é um mineral semelhante à mica,formado essencialmente por silicatos hidratados de alumínio e magnésio, conferindo capacidade de isolante térmico e muito utilizada no cultivo de fungos. A associação entre o óleo de mamona e o óleo de caju tem sido realizada como substituto natural aos ionóforos, com funcionalidades análogas a esses produtos, com a vantagem de serem naturais (OSMARI \& BRANCO, 2012).

Com base no exposto, objetivou - se avaliar o desempenho de bovinos Nelore suplementados com óleos essenciais de caju e mamona, mantidos em pastagens de Brachiáriabrizantha no Estado do Tocantins, afim de contribuir com resultados que validem os efeitos de sua utilização.

\section{Material e métodos}

O experimento foi conduzido na Fazenda Manguari, localizada no município de Porto Nacional, Estado do Tocantins. Utilizou-se um delineamento inteiramente casualizado, onde 120 bovinos da raça Nelore, machos na ocasião do sobreano (18 meses de idade), desverminados com ivermectinae vacinados com vacinas obrigatórias para a região duas vezes ao ano (meses de maio e novembro) e foram separados aleatoriamente em dois grupos com 60 animais cada. 
SOUZA, L.R. et al. Desempenho de bovinos Nelore suplementados com óleos essenciais de caju e mamona, mantidos em pastagens de Brachiária brizantha. PUBVET, Londrina, V. 8, N. 6, Ed. 255, Art. 1692, Março, 2014.

Foram constituídos dois tratamentos, sendo: T1: pastagem de Brachiáriabrizantha+ suplementação mineral sem óleos essenciais; T2: pastagem de Brachiáriabrizantha + suplementação mineral com óleos essenciais $(2,43 \mathrm{~g} / \mathrm{animal} / \mathrm{dia})$. Os suplementos minerais utilizados nos grupos testemunha sem inclusão de óleos essenciais e tratamento com utilização de óleos essenciais estão apresentados na tabela 1.

Tabela 1. Níveis de garantia por quilograma dos suplementos minerais utilizados no experimento da fazenda Maguari no Estado do Tocantins, para os grupos Testemunha e Tratamento.

\begin{tabular}{ccc}
\hline Nutriente & $\begin{array}{c}\text { Testemunha } \\
(\mathbf{T 1})\end{array}$ & Tratamento (T2) \\
\hline Cálcio $(\mathrm{g})$ & 150,00 & 150,00 \\
Fósforo $(\mathrm{g})$ & 60,00 & 60,00 \\
Enxofre $(\mathrm{g})$ & 22,50 & 22,50 \\
Sódio $(\mathrm{g})$ & 159,00 & 159,00 \\
Magnésio $(\mathrm{g})$ & 8,85 & 8,85 \\
Cobalto $(\mathrm{mg})$ & 90,85 & 90,85 \\
Cobre $(\mathrm{mg})$ & $1.063,00$ & $1.063,00$ \\
Iodo $(\mathrm{mg})$ & 73,70 & 73,70 \\
Manganês $(\mathrm{mg})$ & $1.123,00$ & $1.123,00$ \\
Selênio $(\mathrm{mg})$ & 17,10 & 17,10 \\
Zinco $(\mathrm{mg})$ & $3.858,00$ & $3.858,00$ \\
Cardol $(\mathrm{mg})$ & - & 540,00 \\
Cardanol $(\mathrm{mg})$ & - & $2.700,00$ \\
Ácido Ricinoléico & - & $1.215,00$ \\
(mg) & & \\
\hline
\end{tabular}


SOUZA, L.R. et al. Desempenho de bovinos Nelore suplementados com óleos essenciais de caju e mamona, mantidos em pastagens de Brachiária brizantha. PUBVET, Londrina, V. 8, N. 6, Ed. 255, Art. 1692, Março, 2014.

O período experimental teve duração de 60 dias, entre os meses de setembro e novembro de 2012. As variáveis de desempenho avaliadas foram: consumo da mistura mineral e ganho em peso animal. $O$ suplemento mineral era fornecido ad libidum (à vontade) em cochos cobertos e a água disponível em bebedouros artificiais.

A pastagem constituída por Brachiáriabrizantha cv. Marandu apresentava boa disponibilidade de massa, cerca de $50 \mathrm{~cm}$ de altura do solo. Registrou-se ocorrência de chuvas nos últimos 10 dias de período experimental.

O consumo de suplemento foi calculado a partir da quantidade fornecida aos 60 animais de cada tratamento a cada 4 dias.

Os animais foram pesados no início e no final do experimento em balançaprópria para bovinos. A determinação do ganho em peso médio no período (GPMP) foi realizada a partir da diferença de peso final e inicial. Foi estimado também o ganho em peso médio diário (GPMD), tomando como base os 60 dias de tratamento para os dois grupos.

As análises estatísticas foram realizadas pelo programa estatístico SAS Sistema de Análises Estatísticas (SAS, 2006), utilizando-se os procedimentos proc GLM e procmeans, e as médias comparadas pelo teste $t(p<0,05)$.

\section{Resultados e discussão}

Após 60 dias de período experimental, foi avaliado o consumo de suplemento para os dois tratamentos. Os consumos médios para os grupos testemunha e tratamento foram de $165 \mathrm{~g} /$ cabeça/dia e $180 \mathrm{~g} /$ cabeça/dia, respectivamente.

Ressalta-se a inexistência desse tipo de estudo no Brasil, entretanto, existem resultados avaliados com o uso de suplementação mineral protéica. Nesse sentido, MANO (2008) comparou o desempenho Novilhas mestiças Nelore $x$ Red Angus, criadas em piquetes de Tifton 85 (Cynodonssp.) recebendo suplementação protéico-energética em quatro tratamentos: (1) $1 \mathrm{~g}$ de óleos essenciais de caju e mamona/animal/dia; (2) $2 \mathrm{~g}$ de óleos essenciais 
SOUZA, L.R. et al. Desempenho de bovinos Nelore suplementados com óleos essenciais de caju e mamona, mantidos em pastagens de Brachiária brizantha. PUBVET, Londrina, V. 8, N. 6, Ed. 255, Art. 1692, Março, 2014.

de caju e mamona/animal/dia; (3) $4 \mathrm{~g}$ de óleos essenciais de caju e mamona/animal/dia; (4) 0,2g de monensina sódica/animal/dia. Após 63 dias de experimento, observou-se elevados ganhos de peso individual (acima de $0,732 \mathrm{~kg} / \mathrm{dia})$, mas não apresentaram diferenças significativas entre os tratamentos.

CONEGLIAN (2009) avaliou em seu trabalho as melhores dosagens para a utilização de óleos essenciais de caju e mamona em dietas de alto grão sendo recomendadas doses de 2 a 4 gramas/animal/dia. Esses níveis foram capazes de aumentar o pH em 3,4\%, melhorando a degradabilidade da fibra quando comparados à utilização de monensina. A média para as concentrações de ácidos acético, propiônico e butírico dos tratamentos avaliados utilizando níveis de 2, 4 e 8 gramas de óleos essenciais foram de 51:33:16, considerados próximos ao normal encontrado por OWENS \& GOETCH (1986), de 50:35:15 respectivamente.

A dosagem média consumida pelos animais da fazenda Manguari, correspondeu a 2,43 g/animal/dia, estando entre as dosagens recomendadas para a melhoria do pH e concentrações de ácidos graxos de cadeia curta.

As pesagens iniciais não mostraram diferença estatística entre os pesos do grupo testemunha e tratamento deste estudo (tabela 2), mas apresentaram diferença significativa pelo teste $t(p<0,05)$ na pesagem final do período experimental, mostrando aumento no ganho em peso dos animais a partir da utilização dos óleos essenciais de caju e mamona na suplementação mineral. O ganho em peso médio no período experimental foi de $6,53 \mathrm{~kg}$ para o grupo testemunha e $17,36 \mathrm{~kg}$ para o grupo tratamento. Ambos apresentaram GPMD de 0,109 kg/animal/dia e 0,289 kg/animal/dia, respectivamente (tabela 3), provavelmente pela boa disponibilidade de massa foliar existente, pois sabe-se que os suplementos minerais convencionais somente, não promovem ganho em peso no período seco do ano, quando na maioria dos casos existe baixa disponibilidade de forragem e baixa qualidade da fibra ingerida. 
SOUZA, L.R. et al. Desempenho de bovinos Nelore suplementados com óleos essenciais de caju e mamona, mantidos em pastagens de Brachiária brizantha. PUBVET, Londrina, V. 8, N. 6, Ed. 255, Art. 1692, Março, 2014.

Tabela 2. Valores mínimos, médios, desvios-padrões, máximos e número amostral $(\mathrm{N})$ do peso inicial e peso final de novilhos da raça Nelore do rebanho da fazenda Manguari, TO submetidos a dois tipos diferentes de tratamentos.

\begin{tabular}{|c|c|c|c|c|}
\hline & \multicolumn{2}{|c|}{ Peso Inicial } & \multicolumn{2}{|c|}{ Peso Final } \\
\hline & Testemunha & Tratamento & Testemunha & Tratamento \\
\hline Mínimo (Kg) & 310 & 300 & 320 & 325 \\
\hline \multirow{2}{*}{ Média $\pm D P(K g)$} & 361,94 & 366,11 & 368,47 & 383,47 \\
\hline & $\pm 19,89^{\mathrm{ns}}$ & $\pm 23,10^{\mathrm{ns}}$ & $\pm 19,85^{*}$ & $\pm 20,45^{*}$ \\
\hline Máximo $(\mathrm{Kg})$ & 400 & 395 & 410 & 425 \\
\hline $\mathrm{N}$ & 60 & 60 & 60 & 60 \\
\hline
\end{tabular}

A tabela 3 dada abaixo apresenta os resultados referentes ao desempenho de animais da raça Nelore no grupo testemunha e tratamento da fazenda Manguari, TO.

Tabela 3. Ganho em peso Médio no Período (GPMP) e Ganho em Peso Médio Diário (GPMD) em 60 dias experimentais, de novilhos da raça Nelore do rebanho da fazenda Manguari, TO submetidos a dois tipos diferentes de tratamentos.

\begin{tabular}{ccl}
\hline & Testemunha & Tratamento \\
\hline GPMP $(\mathrm{kg})$ & 6,53 & 17,36 \\
GPMD $(\mathrm{kg})$ & 0,109 & 0,289 \\
\hline
\end{tabular}

*Cálculos obtidos pela diferença de peso médio final e inicial. 
SOUZA, L.R. et al. Desempenho de bovinos Nelore suplementados com óleos essenciais de caju e mamona, mantidos em pastagens de Brachiária brizantha. PUBVET, Londrina, V. 8, N. 6, Ed. 255, Art. 1692, Março, 2014.

Os resultados obtidos contrariaram os estudos realizados por ZANETTI ET AL. (2000), ao avaliarem o desempenho de novilhas e novilhos consumindo quatro tipos de suplementos comerciais, incluindo suplemento mineral convencional em pastagem de Brachiáriadecumbens com boa disponibilidade de massa foliar no período seco do ano, mais cana de açúcar. Os ganhos em peso observados foram negativos para a utilização de suplemento mineral convencional sem uréia (-96 gramas/animal/dia), mas positivos para a utilização de suplemento mineral com uréia (91\%PB) com ganho em peso de 207 gramas/animal/dia. Tais resultados obtidos no presente experimento com utilização de óleo de caju e mamona na suplementação mineral convencional se assemelham aos valores obtidos por este mesmo autor ao utilizar suplementação mineral com uréia.

O consumo de suplementos minerais $(25 \mathrm{~g} / 100 \mathrm{~kg} /$ peso vivo corporal) enriquecidos com virginiamicina na dosagem de $35 \mathrm{mg} / 100 \mathrm{~kg} /$ peso vivo corporal são recomendadas pela empresa detentora da molécula. Foram observados ganhos em peso médio diário nos meses de abril à julho de 0,180 $\mathrm{kg} / \mathrm{animal} / \mathrm{dia}$ ao fornecer este suplemento para bovinos de corte em pastagem de BrachiariaBrizantha(PHIBRO, 2012).

SOARES (2005) registrou perda de peso de 83 gramas/animal/dia no inverno, utilizando $12 \%$ de oferta de forragem. Os ganhos avaliados neste experimento foram considerados positivos, visto que neste período em geral, os animais tendem a perder até $30 \%$ do peso vivo corporal pela baixa disponibilidade e qualidade de forragem; deficiência de minerais; prejuízos no crescimento microbiano e redução na degradabilidade da forragem (GARCIA, 2008).

\section{Conclusão}

Tendo em vista os resultados encontrados neste estudo recomenda-se a utilização de óleos essenciais de caju e mamona na suplementação mineral para bovinos de corte no período seco do ano. 
SOUZA, L.R. et al. Desempenho de bovinos Nelore suplementados com óleos essenciais de caju e mamona, mantidos em pastagens de Brachiária brizantha. PUBVET, Londrina, V. 8, N. 6, Ed. 255, Art. 1692, Março, 2014.

Mais estudos devem ser realizados a fim de consolidar os resultados observados e avaliar a relação custo-benefício da utilização desses aditivos naturais na alimentação de bovinos de corte.

\section{Referências bibliográficas}

CARLOTO, M.N. Suplementação de bovinos na estação seca. Universidade Federal de Mato Grosso do Sul. Campo Grande/MS. 2008. 23p.

CONEGLIAN, S.M. Uso de óleos essenciais de mamona e caju na dieta de bovinos. 2009. 100p. Tese (Doutorado em Zootecnia). UEM/PR. Maringá. 2009.

COAN, R.M; GRANDINI, D. Estratégias de Suplementação para a seca: Custos e Resultados.Online. Disponível em: http://www.bigma.com.br/artigos.asp?id=170. Acesso em: 02 de novembro de 2012.

GARCIA, R.P.A. Suplementação protéica e mineral de novilhas gestantes em pastagem nativa dominada por capim- Annoni-2. 2008. 80p. Dissertação (Mestrado em Zootecnia).UFSM/RS. Porto Alegre. 2008.

IBGE- INSTITUTO BRASILEIRO DE GEOGRAFIA E ESTATÍSTICA. Indicadores IBGE. Estatística da Produção Pecuária. 2012. 35p.

MANO, D.S. Desempenho produtivo e econômico da adição de óleos essenciais na suplementação de novilhas em pastagem de Cynodonssp. 2008. 75p. Dissertação (Mestrado em Zootecnia). UEM/PR, Maringá, 2008.

OWENS, F.N.; GOETSCH, A.L. Ruminal fermentation.In: $\mathrm{CHURCH,} \mathrm{D.C.} \mathrm{(Ed).} \mathrm{The} \mathrm{ruminant}$ animal digestive physiology and metabolism. New Jersey: Prentice Hall, p.145-171, 1986.

PHIBRO. Animal Heath Corporation. Promotores de eficiência alimentar. Online.Disponível em: http://www.vitamais.com.br/midia/ultimos_dados_VM.pdf. Acesso em 09 de novembro de 2012.

SAS Institute. SAS Technical Report. SAS/STAT software: Changes and Enhancement, Release 9.1. 3, Cary NC: SAS Institute. 2006.

SEGABINAZZI, L.R. Aditivo a base de extratos vegetais comoalternativa à monensina sódica na dieta de vacas de corte terminadas em confinamento. 2008. 82p. Dissertação (Mestrado em Zootecnia). UFSM/RS, Santa Maria, 2008.

SOARES, A.B, et al. Produção Animal e de Forragem em pastagem nativa submetidas a distintas ofertas de forragem. Ciência Rural. Santa Maria, v.35, n.5, p.1148-1154. 2005.

ZANETTI, M.A.; et al. Desempenho de novilhos consumindo suplemento mineral proteinado, convencional ou com uréia. Revista Brasileira de Zootecnia. Viçosa, v. 29, n.3, p. 935-939, 2000. 